\title{
Hydrokinetic Energy Opportunity for Rural Electrification in Nigeria
}

\author{
Ogunjuyigbe Ayodeji Samson Olatunji, Ayodele Temitope Raphael ${ }^{*}$ and Ibitoye \\ Tahir Yomi
}

\author{
Power Energy Machine and Drives (PEMD) Research Group, Electrical and Electronic Engineering Department, Faculty \\ of Technology, University of Ibadan
}

\begin{abstract}
This paper is part of the ongoing research by the Power, Energy, Machine and Drive (PEMD) research group of the Electrical Engineering Department of the University of Ibadan. The paper presents various sites with possible hydrokinetic energy potential in Nigeria with the aim of quantifying their energy potential for rural electrification application. Overview of hydrokinetic technology is also presented with the view of highlighting the opportunities and the challenges of the technology for rural electrification. A case study of using hydrokinetic turbine technology in meeting the energy demand of a proposed civic center in a remote community is demonstrated. Some of the key findings revealed that Nigeria has many untapped hydrokinetic potential site and if adequately harnessed can improve the energy poverty and boost economic activities especially in the isolated and remote rural communities, where adequate river water resource is available. The total estimated untapped hydrokinetic energy potential in Nigeria is $111.15 \mathrm{MW}$ with the Northern part of the country having $68.18 \mathrm{MW}$ while the Southern part has 42.97MW. The case study shows that harnessing hydrokinetic energy of potential site is promising for rural electrification. This paper is important as it will serve as an initial requirement for optimal investment in hydrokinetic power development in Nigeria.
\end{abstract}

Keywords: Hydrokinetic, Hydro-turbine, Nigeria, Rural Electrification

Article History: Received November 16 ${ }^{\text {th }}$ 2017; Received in revised form April 7th 2018; Accepted April 15 th 2018; Available online How to Cite This Article: Olatunji, O.A.S., Raphael, A.T. and Yomi, I.T. (2018) Hydrokinetic Energy Opportunity for Rural Electrification in Nigeria. Int. Journal of Renewable Energy Development, 7(2), 183-190.

http://dx.doi.org/10.14710/ijred.7.2.183-190

\section{Introduction}

In recent time, there is noteworthy interest in hydrokinetic potential globally for power generation using 'zero head' or hydrokinetic turbines, which require no dams. Nigeria is blessed with copious Renewable Energy Sources (RES) that is harmless, clean, and affordable (Sambo 2009). This RES can be optimally used in solving the challenges of increasing energy demand, cost and adverse effects of fossil fuels. In addition, it can help to combat the increasing health hitches that arise from the use of other conventional energy sources. Renewable energy technologies offer many environmental benefits over conventional energy sources (Kaygusuz and Kaygusuz 2002). The use of electrical energy plays a vital role in economic growth and development of the people's standard of living. It has been reported by Bertsch (2015) that though one-third of the world's population have access to moving water but not to electricity.

Majority of the rural residents in Nigeria have low standard of living and have limited access to modern amenities like (road, school, communication, etc). Despite the efforts in the direction of rural electrification, progress and success rates remain low because of harsh operating conditions, limited resources as well as poor planning (Anyi et al. 2010). The living standards of the rural Nigerians can be improved by the provision of electricity which is often require to power their loads such as lighting, communication (radio and television), cooling, etc (Anyi et al. 2009). Rural electrification can be addressed using techniques such as diesel generators, grid-extension and/or renewable energy systems (such as wind, solar, hydro, etc)(Ayodele 2014). However, gridextension to rural areas is expensive due to low consumption and poor load factors. This is definitely an unappealing option since most rural residents in Nigeria are poor and thus unable to afford electrical services (Zomers 2003, Ayodele et al. 2016).

Hydrostatic and hydrokinetic methods are the main methods of harnessing energy from water. Hydrostatic method is the traditional way of generating electricity by storing water in reservoirs to create a water head and extracting the potential energy of water through suitable turbine (Khan et al. 2008). In hydrokinetic method, the kinetic energy of the flowing rivers is captured and

\footnotetext{
* Corresponding author: tayodele2001@yahoo.com
} 
converted into electricity by relatively small scale turbines known as hydrokinetic turbines with no head (Kusakana 2015). Hydrokinetic energy technologies have some advantages over the traditional hydropower system. Some of these advantages are: minimum amount of civil work is required; there is no need for acceptable water head and easy installation in free flowing water (Khan et al. 2008).

As a result of the simple design of the hydrokinetic power system and the natural endowment, there are theoretically huge numbers of potentials sites in Nigeria as compared to small hydropower generation. The cost of generating hydrokinetic is lower than that of small hydropower (Kusakana 2015). Hydrokinetic technology is more economical compared to some other sources of renewable technologies (solar, wind, etc).This paper therefore present the potential of utilizing hydrokinetic technology in Nigeria for rural electrification in places where adequate water resource are available.

\section{Hydrokinetic Technology}

Hydrokinetic technology is currently receiving global attention with the intention of overcoming the problems associated with the traditional hydropower generation. Hydrokinetic technologies convert kinetic energy from flowing water into electricity, or other forms of energy (Güney and Kaygusuz 2010). Hydrokinetic turbine (HKT) is connected to a generator which will be turn by the blades of the turbine to produce electricity directly from the flowing water in a river stream. The following advantages of the technology are identified over the conventional hydropower: No construction of dam is needed and hence problem associated with massive construction of reservoir is removed; hydrokinetic turbine does not require head which makes the technology suitable for any site, the direction of river flow does not change unlike the wind and solar technology which require additional component to track the direction of the wind/solar. In hydrokinetic technology, no destruction of land and re-settlement as the technology basically rely only on existing kinetic energy in the water stream.

\subsection{Hydrokinetic turbine}

The operation principles of the hydrokinetic turbines are similar to that of wind turbines. They are designed to extract the kinetic energy of flowing water, driving a generator to produce electricity. Hydrokinetic turbine systems are practically zero-head turbines and are not constrained in a confined environment which makes them different from small hydro turbine systems. Small hydro turbines make used of a penstock that transports pressurized water from an elevated hydraulic head. As a consequence of the confined flow and the associated turbine designs, the efficiency of small hydro turbines can be approximately $90 \%$ (Khan et al. 2009).

The most common hydrokinetic turbine designs are vertical and horizontal axis. Although, they both execute similar function of extracting kinetic energy from the rivers and ocean, each of the turbines has its own design and performance advantages. The turbines can be mounted in three ways either as bottom structure mounted, floating structure mounted and near surface structure mounted (Ogunjuyigbe et al. 2015). The various types of hydrokinetic turbines as illustrated in Figure 1 are classified into three major groups: horizontal axis, vertical axis and cross-flow turbines. The turbines under various classifications are depicted in Figures 2 and 3.

Hydrokinetic turbines operate at lower energy extraction efficiency when compared with small hydropower turbines (Faure et al. 1986). The propeller type of turbine has theoretical efficiency limit of $59.3 \%$ (Betz limit) (Gorban et al. 2001). In practice hydrokinetic turbines operate with efficiencies between $16 \%$ and $42 \%$, depending on the hydraulic conditions of the turbine (Faure et al. 1986, Gorban et al. 2001).

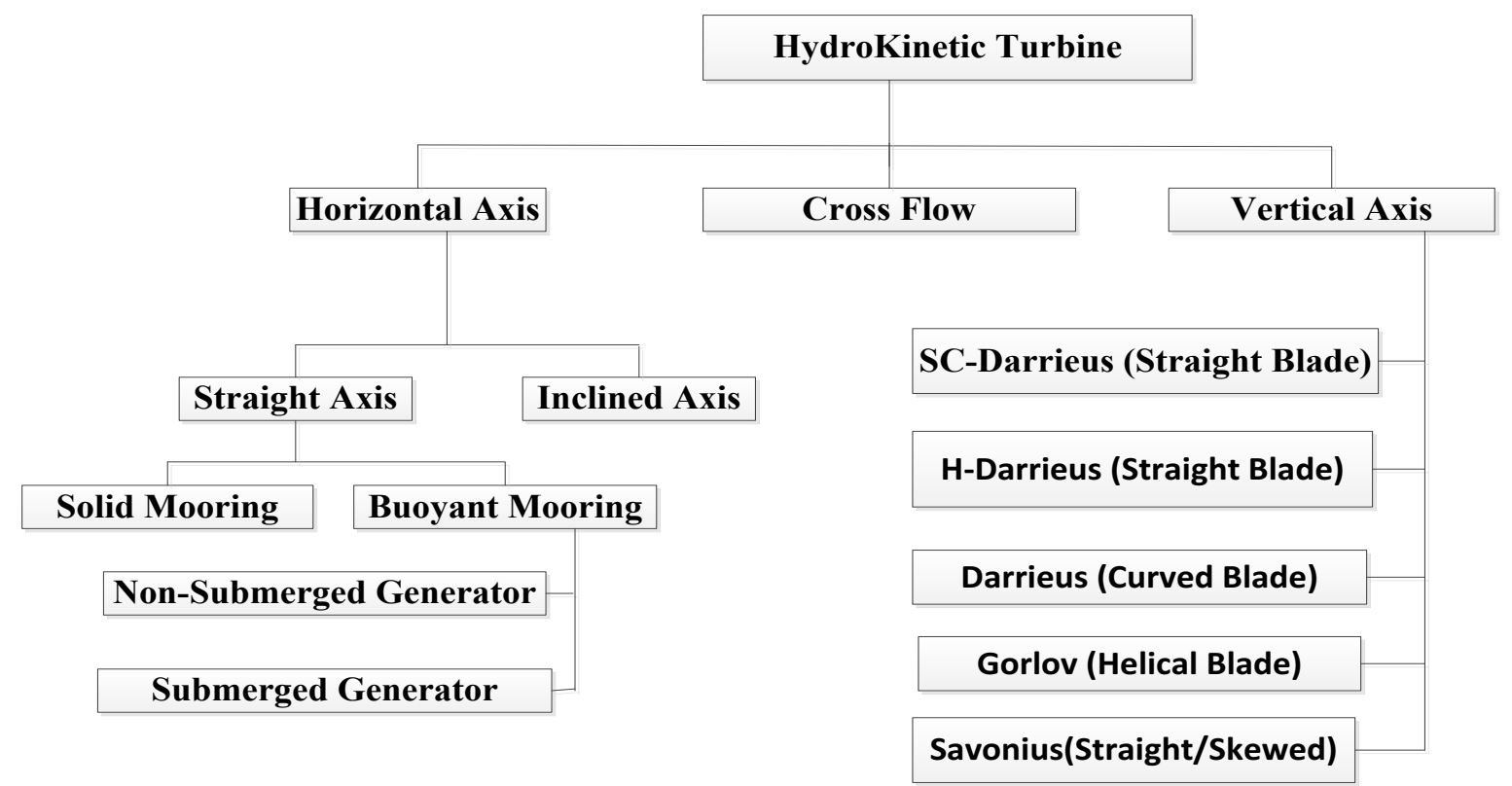

Figure 1 .Classification of Hydrokinetic Turbines (Khan et al. 2009) 


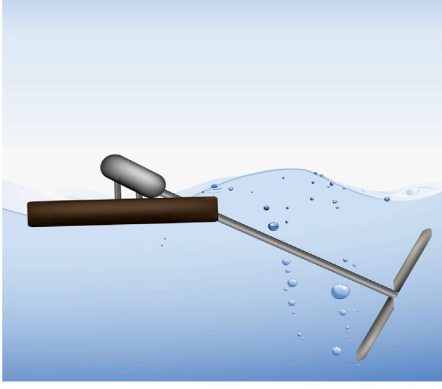

(a) Inclined axis

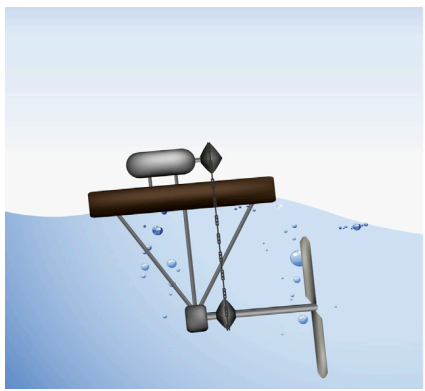

(c) Non-submerged

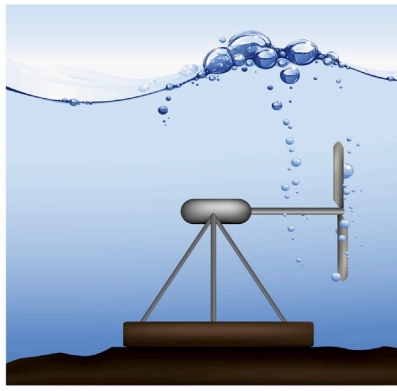

(b) Solid mooring

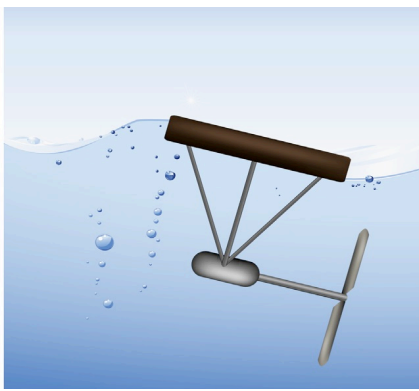

(d) Submerged
Figure 2. Horizontal axis hydrokinetic turbines (Vermaak et al. 2014)

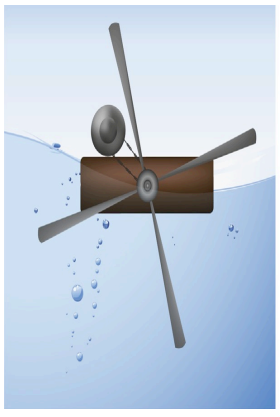

(a)In-Plane Axis

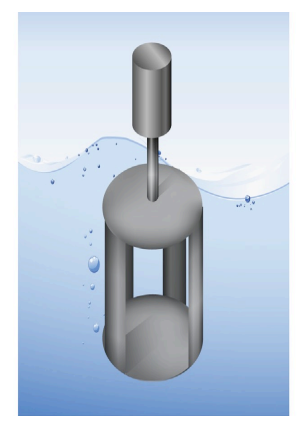

(b)Squirrel Cage Darrieus

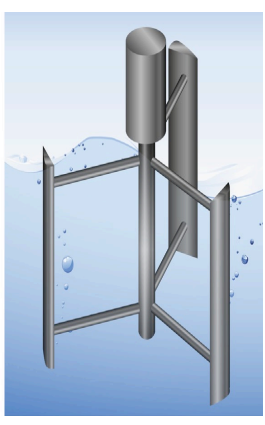

(c) H-Darrieus

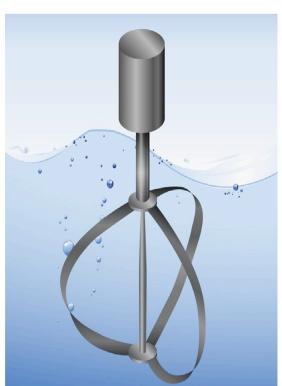

(a) Darrieus

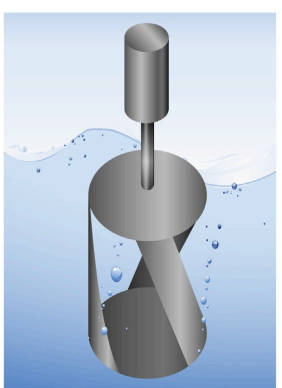

(b) Gorlov

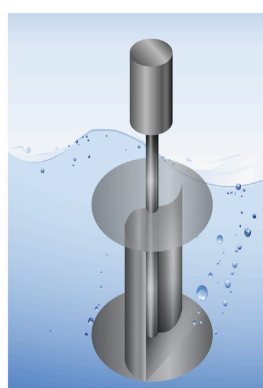

(c) Savonius
Figure 3. Vertical axis hydrokinetic turbines (Vermaak et al. 2014)

Vertical axis hydrokinetic wind turbines have the following advantages: It is not dependent on the direction of current, the blades are very easy to construct and the span of the blade can be easily increased. However, the efficiency is slight lesser than horizontal turbine and the fixed blade does not start naturally. The horizontal axis wind turbine has the advantages of being more efficiency and the technology is more matured compared to the vertical turbine (Coiro 2007). However, the turbine depends on the direction of stream current and it requires complex mechanism for blade rotation

\section{Opportunities and Challenges of Harnessing Hydrokinetic Energy in Nigeria}

This section presents the opportunities and the possible potential of hydrokinetic energy for electricity generation in rural community in Nigeria.

\subsection{Opportunities of hydrokinetic}

The demand for renewable energy is expected to increase significantly in the nearest future as it is expected that more rural community will be electrified. According to United States Energy Information Administration; the world electricity consumption will likely increase by $73 \%$ between 1999 and 2020 especially from Sub-Sahara Africa where the population is fast growing. Hydrokinetic energy has great potential to bridge this gap in Nigeria as there are presently abundant flowing river in the rural villages across the country that are yet to be tapped. Exploitation and utilization of this ample potential in Nigeria would provide opportunity in boosting the socio-economic activities in the local communities. Hydrokinetic technology can offer opportunity for cheap and affordable rural electrification for meeting the basic needs which can improve the quality of life of the rural dwellers. The BTS station which houses the communication equipment can also be powered by hydrokinetic power thereby providing good communication that can reduce ruralurban migration. Similarly, the small scale business such as "gari" processing industries can be enhanced by supply from hydrokinetic source, thereby empowering the rural dwellers and improving their economic values. Furthermore, social life will be boosted which can promote unity within the community as community halls and central buildings can be powered using this technology

\subsection{Possible challenges of utilizing hydrokinetic technology in Nigeria}

Despite the great opportunities and high enthusiasm in this field, skepticism on technological feasibility still exists. Many technologies's related questions are being put forward continuously in addition to fundamental inquiries (availability of resources, area of application). The possible challenges in developing hydrokinetic technology in Nigeria are briefly highlighted in the succeeding sub-section.

\subsubsection{Resource assessment}

One of the possible problems militating against hydrokinetic development in Nigeria is lack of adequate information due to limited research on hydrokinetic resource assessment in the country. There is need to identify resourceful sites to harness hydrokinetic energy. This would necessitate an investigation of macro and micro scale site assessment, determination of annual energy yield and analysis of river characteristics. Presently, this is lacking for hydrokinetic energy as most of the assessments done in Nigeria are in support of 
Citation: Olatunji, O.A.S., Raphael, A.T. and Yomi, I.T. (2018) Hydrokinetic Energy Opportunity for Rural Electrification in Nigeria. Int. Journal of Renewable Energy Development, 7(2), 183-190, doi.org/10.14710/ijred.7.2.183-190

$\mathrm{P}$ a g e 186

conventional small hydropower generation (Manohar and Adeyanju 2009) and not for hydrokinetic generation. Hence, lack of databases for hydrokinetic potential in the country is a major challenge.

\subsubsection{Climatic condition}

The main drawback of hydrokinetic technology is its resource-dependent power output and its reliance on weather and climatic condition (Chen et al. 2007). Nigeria has two main seasons: the Wet season between April -September and the dry season between OctoberMarch. Thus, it cannot always produce sufficient energy to match the fluctuating load requirements continuously throughout the year without the use of energy storage system (Kusakana 2015) especially in the dry season. This often form one of the reasons the investors are shying away from such technology. Similarly, the advantages of hybridization with other RES may be employed to overcome this limitation.

\subsubsection{Economics viability}

The most prevailing factor that hinders the success of most energy technologies is the associated cost of installation. This includes: the capital cost, operations and maintenance cost, scalability, simplicity of design, applications diversity, material and labor engagement. Several other factors that may affect the cost indirectly are system reliability, societal acceptance and system performance (Khan et al. 2008). Due to this various economic and social constraint in addition to the small population in the rural communities, government and private company are always reluctant to invest in this kind of adventure as it always considered being uneconomical due to the small population.

\section{Estimation of Nigerian Hydrokinetic Energy Potential}

The kinetic energy of flowing water can be determined from the density of the water, the velocity at which the water flows and the cross-sectional area at which the energy will be extracted. The hydrokinetic energy available in a mass of flowing river can be determined using:

$$
P=\frac{1}{2} \rho A v^{3}
$$

but

$$
Q=v A
$$

therefore, the hydrokinetic potential expressed in (1) can be re-written as:

$$
P=\frac{1}{2} Q v^{2}
$$

where, $P$ is the hydrokinetic power/available kinetic power; $\rho$ is the water density $\left(1000 \mathrm{Kgm}^{3}\right), A$ is the cross sectional area of extraction $\left(\mathrm{m}^{2}\right), Q$ is the discharge rate $\left(\mathrm{m}^{3} \mathrm{~s}^{-1}\right), v$ is the water flow velocity $(\mathrm{m} / \mathrm{s})$.
Hydrokinetic power potential is often reported as a power density which is the power normalized to a unit area.

$P_{d}=\frac{P}{A}=\frac{1}{2} \rho v^{2}$

Also, hydrokinetic energy density (energy potential) can be written as:

$E_{d}=E_{d} \times t$

The power and energy generated by a given hydrokinetic turbine are given as follows, respectively:

$P_{H K T}=P_{d} \times A \times C_{P}$

$E_{H K T}=P_{H K T} \times t$

where $C_{P}$ is the coefficient of performance of the hydrokinetic turbine, $v$ is the water velocity $(\mathrm{m} / \mathrm{s})$ and $t$ is the duration of power supply (hours)

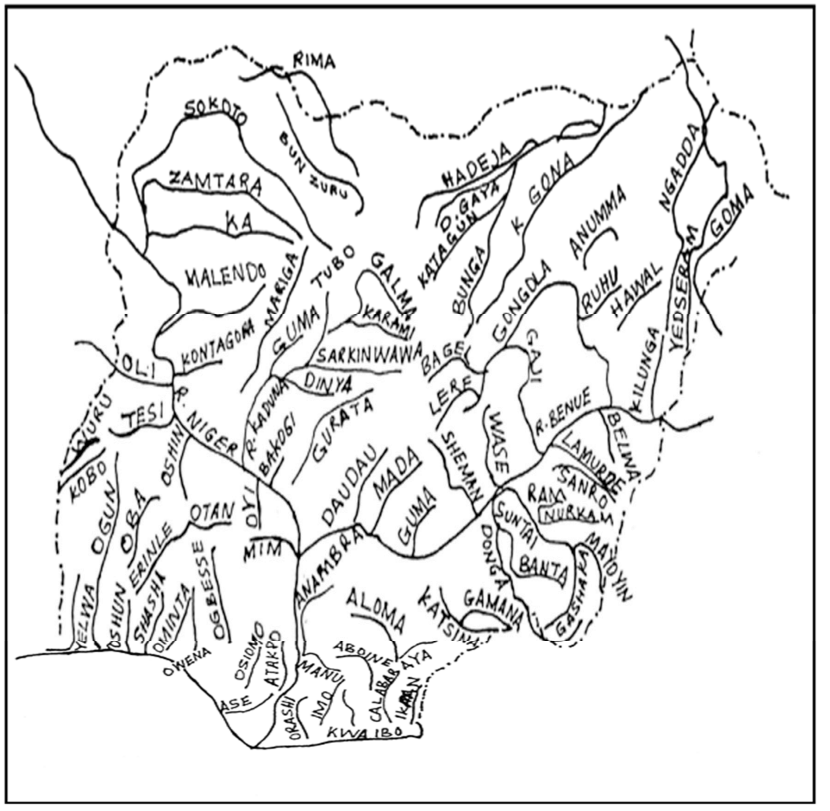

Figure 4. Map of Nigeria showing some major rivers (F.A.O 2012)

When considering flows in rivers, one can make the reasonable assumption that the density $(\rho)$ remains constant, even with changes in temperature. The discharge rate, area and velocity remain the only variables parameters required to determine the kinetic power. The calculation of the kinetic power depends on either the discharge rate or cross section area which is either the river cross-sectional area or the area of the device (turbine) that will be used to extract the kinetic energy. For the purposes of this study and to generalize the power potential over such a large land mass, the river cross sectional area will be used. Figure 4 illustrates the spread of rivers across the country designating the extent of hydrokinetic potential in the country 
Table 1.

Some Rivers in Nigeria and their Average Discharge (Zarma 2006)

\begin{tabular}{llc}
\hline Location & River & Average Discharge ( $\left.\mathbf{m}^{3} / \mathbf{s}\right)$ \\
\hline Danko & Niger & 1650 \\
Jebba & Niger & 1767 \\
Zungeru II & Kaduna & 343 \\
Zungeru I & Kadunai & 294 \\
Shiroro & Kaduna & 55 \\
Zurubu & Kaduna & 55 \\
Gwaram & Jamaare & 75 \\
Izom & Gurara & 55 \\
Gudi & Mada & 41.5 \\
Kafancha & Kongum & 2.2 \\
Kurra II & Sanga & 5.5 \\
Richa II & Dafo & 4.0 \\
Richa I & Mosari & 6.5 \\
Mistakuku & kurra & 2.0 \\
Kombo & Gongola & 128 \\
kiri & Gongola & 154 \\
kramti & Kam & 80 \\
Beli & Taraba & 266 \\
Garin Deli & Taraba & 323 \\
Sarkin & Suntai & 20 \\
Dango & Donga & 45 \\
Gembu & Kastina Ala & 170 \\
kasimbila & Kastina Ala & 740 \\
Markurdi & Benue & 3185 \\
Lokoja & Niger & 6253 \\
Onisha & Niger & 6635 \\
Ifon & Osse & 80 \\
Ikom & Cross & 759 \\
Afikpo & Cross & 1621 \\
\hline
\end{tabular}

The annual rainfall ranges between 500 and $1000 \mathrm{~mm}$ in the arid North and between 1,500 and 4,000 $\mathrm{mm}$ in the southern region, the country experiences flowing rivers and streams for two-thirds of the year (F.A.O 2012).River Niger and Benue are the major rivers in Nigeria with average discharge of $5589 \mathrm{~m}^{3 / \mathrm{s}}$ and $3400 \mathrm{~m}^{3} / \mathrm{s}$ respectively (Olatunde and Oladele 2013). The list of some flowing rivers in Nigeria and their average discharge and their specific locations is presented in Table 1

\section{Case study}

In this section, a case study is presented for a typical isolated rural community with about 10 households located close to river in the Southern part of Nigeria. Hydrokinetic energy is offered to meet the energy demand of proposed civic center for the remote village. The main occupation of the duelers are fishing and farming. The civic center would serve as a central point where villagers would charge phones and their rechargeable electronics. The center is also expected to serve as common meeting point where the inhabitants can socialize. The daily load profile depicting the energy requirement of the civic center is depicted in Figure 5 with average power demand of about $1 \mathrm{~kW}$ with a peak load of $1.38 \mathrm{~kW}$.

The kinetic energy of the flowing rivers is captured and converted into electricity by relatively small-scale turbines. The average water velocity of the river close to the community is about $1.2 \mathrm{~m} / \mathrm{s}$ it was observed to flow with almost constant velocity throughout the day as depicted in Figure 6

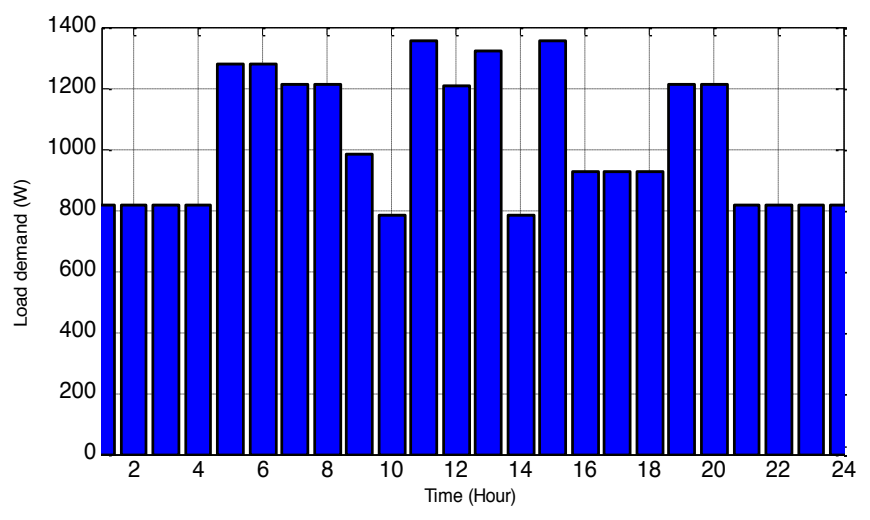

Figure 5. Load profile for the proposed civic center

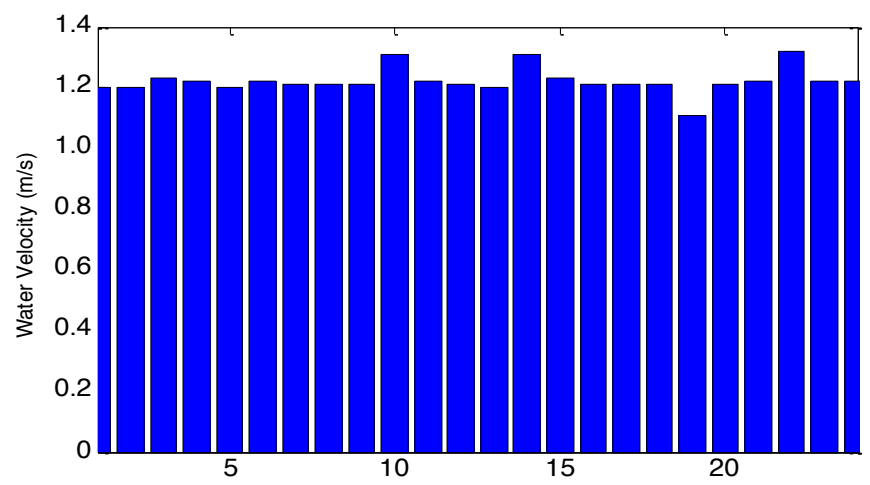

Figure 6. Water velocity for the available river close to the village 
In order to ensure smooth supply of energy throughout the day, The hydrokinetic turbine is made to supply electrical power to the load through the DC bus consisting of battery. Hence the total energy supply to the loads come from hybrid of hydrokinetic turbine and the battery as depicted in Figure 7

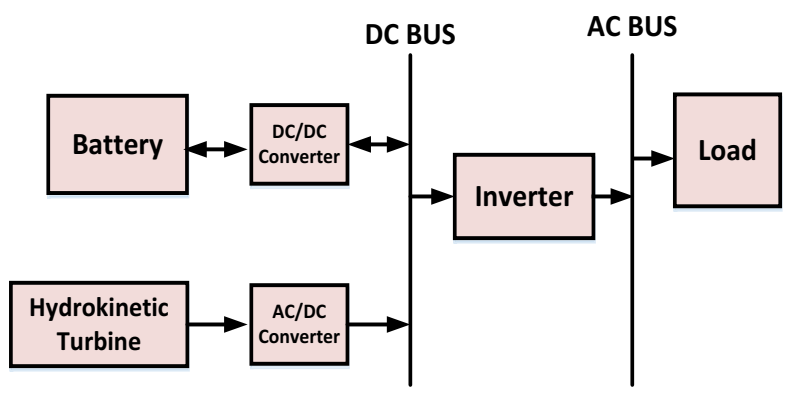

Figure 7. hybrid configuration of hydrokinetic and battery

The total energy supply to the load at time $t$ (i.e. energy from battery and hydrokinetic turbine) can be written as:

$$
E(t)=E_{H K T}(t)+E_{B a t t}(t)
$$

The required storage capacity of the battery system in Ampere-hour (Ah) can be determined using:

$$
M_{\text {batt }}=\frac{A_{d} \times E_{L}}{\eta_{\text {batt }} \times \eta_{\text {inv }} \times D o D \times U_{s}}
$$

where $A_{d}$ is the battery autonomous days (i.e. the maximum number of days the battery can supply continuous energy without a recharge by Hydrokinetic energy source), DoD is maximum permissible depth of discharge of the battery and $U_{s}$ is the system voltage in Volts, $\eta_{\text {batt }}$ is the Efficiency of inverter (\%), $\eta_{i n v}$ Efficiency of inverter (\%), $E_{L}$ is the total energy demand.

The battery charges when the power from hydrokinetic source is greater than the total load demands. The excess power is ultilised to charge the battery. However, power is drawn from the battery (discharging) whenever the load demands is greater than the power output of the hydrokinetic generator (i.e power deficit). The state of charge of the battery at time $(t)$ is given as:

$$
\begin{aligned}
& \operatorname{SOC}(t)=\operatorname{SOC}(t-1) \cdot(1-\sigma)+\left(E_{H K T}(t)-\frac{E_{L}(t)}{\eta_{i n v}}\right) \cdot \eta_{B}, \operatorname{charging}(10) \\
& \operatorname{SOC}(t)=\operatorname{SOC}(t-1) \cdot(1-\sigma)+\left(\frac{E_{L}(t)}{\eta_{i n v}}-E_{H K T}(t)\right), \text { discharging (11) }
\end{aligned}
$$

The basic parameters used in simulating the battery storage are shown in Table 2

Table 2

Battery storage parameters for the simulation

\begin{tabular}{lllllll}
\hline Parameter & $\begin{array}{l}A_{d} \\
\text { (days) }\end{array}$ & $\mathrm{DoD}$ & $\begin{array}{c}U_{s} \\
\text { (volt) }\end{array}$ & $\eta_{\text {batt }}$ & $\eta_{\text {inv }}$ & $\begin{array}{c}M_{\text {batt }} \\
(\mathrm{Ah})\end{array}$ \\
\hline Values & 2 & $60 \%$ & 12 & 0.9 & 0.9 & 350 \\
\hline
\end{tabular}

\section{Result and Discussion}

This section presents the results quantifying the available hydrokinetic energy potential in various part of Nigeria. It also presents the results showing the potential of using hydrokinetic turbine in meeting the electrical energy needs of rural community with good water resources.

\subsection{Hydrokinetic potential in Nigeria}

The hydrokinetic power potential of the flowing rivers depicted in Table 1 is evaluated using (4) given the average velocity of flowing river in Nigeria as $3 \mathrm{~m} / \mathrm{s}$. The sites are classified into two (The Northern and Southern), this is to allow us understand the hydrokinetic potential in the Northern and Southern part of the country. The estimation hydro kinetic potential in the Northern Nigeria is depicted in Table 3 while that of southern Nigeria in shown in Table 4.

Table 3

Estimated Hydrokinetic Power (MW) and Energy Potential (MWh) of Rivers Located in Northern Nigeria

\begin{tabular}{llcc} 
Location & River & $\begin{array}{l}\text { Hydrokinetic } \\
\text { Power } \\
\text { Density } \\
\left(\mathrm{MW} / \mathrm{m}^{2}\right)\end{array}$ & $\begin{array}{l}\text { Hydrokinetic } \\
\text { Energy } \\
\text { density } \\
\left(\mathrm{MWh} / \mathrm{m}^{2}\right)\end{array}$ \\
\hline Gwaram & Jamaare & 0.3375 & 8.1 \\
Kafancha & Kongum & 0.0099 & 0.2376 \\
Kombo & Gongola & 0.576 & 13.824 \\
Kiri & Gongola & 0.711 & 17.064 \\
Beli & Taraba & 1.197 & 28.728 \\
Garkin & Suntai & 0.09 & 2.16 \\
Danko & Donga & 0.2025 & 4.86 \\
Gembu & Kastina Ala & 0.765 & 18.36 \\
Zurubu & Kaduna & 0.2475 & 5.94 \\
Zungeru & Kaduna & 1.5435 & 37.044 \\
Shiroro & Kaduna & 1.323 & 31.752 \\
Donko & Niger & 7.425 & 178.2 \\
Jebba & Niger & 7.9515 & 360 \\
Kasimbila & Kastina Ala & 3.33 & 79.92 \\
Makurdi & Benue & 14.3325 & 343.98 \\
Lokoja & Niger & 28.1385 & 675.324 \\
\hline Total & & 68.18 & 1805.4936 \\
\hline
\end{tabular}

\begin{tabular}{|c|c|c|c|}
\hline Location & River & $\begin{array}{l}\text { Hydrokinetic } \\
\text { Power Density } \\
\left(\mathrm{MW} / \mathrm{m}^{2}\right)\end{array}$ & $\begin{array}{l}\text { Hydrokinetic } \\
\text { Energy density } \\
\left(\mathrm{MWh} / \mathrm{m}^{2}\right)\end{array}$ \\
\hline Onitsha & Niger & 29.857 & 716.568 \\
\hline Ifon & Ose & 0.36 & 8.64 \\
\hline Ikom & Cross & 3.4153 & 81.9672 \\
\hline Afikpo & Cross & 7.2945 & 175.068 \\
\hline Ajura & Ogun & 0.23967 & 5.75208 \\
\hline Apoje & Osun & 1.8025 & 43.26 \\
\hline \multicolumn{2}{|c|}{ Total } & 42.97 & 1031.255 \\
\hline
\end{tabular}

Table 4.

Hydrokinetic Power (MW) and Energy (MWh) Potentials of some Rivers Located in Southern Nigeria

From Table 3, it is observed that river Niger (Lokoja) and Benue has the highest potential for hydrokinetic power in the Northern part of Nigeria with power density values of $28.43 \mathrm{MW} / \mathrm{m}^{2}$ and $14.33 \mathrm{MW} / \mathrm{m}^{2}$, respectively. The rivers also have energy density of $675.324 \mathrm{MWh} / \mathrm{m}^{2}$ 
and $343.98 \mathrm{MWh} / \mathrm{m}^{2}$. The total hydrokinetic power and energy potential in the North was estimated to be 68.18 $\mathrm{MW} / \mathrm{m}^{2}$ and $1805.4936 \mathrm{MWh} / \mathrm{m}^{2}$, respectively. Table 4 reveals that river Niger (Onitsha) and Cross (Afikpo) has the highest power potential for hydrokinetic power in southern Nigeria with the value of $29.86 \mathrm{MW} / \mathrm{m}^{2}$ and $7.29 \mathrm{MW} / \mathrm{m}^{2}$, respectively. The total power and energy potential of hydrokinetic power generation in the Southern part is estimated as $42.97 \mathrm{MW} / \mathrm{m}^{2}$ and 1031.255 MWh $/ \mathrm{m}^{2}$. This demonstrates that the country has an estimated total power of $111.15 \mathrm{MW} / \mathrm{m}^{2}$ untapped hydrokinetic potential spread across the nation. This can be used to help meet some of the energy needs of some rural villages.

\subsection{Meeting load demand of an isolated community using hybrid of hydrokinetic and battery.}

Load audit of a proposed civic center was conducted for a typical village with the intention of meeting the electrical requirement of the building using the available water resource within the community. The average load requirement of the center was determined to be about $1 \mathrm{~kW}$. The center is thought to improve the social life of the villagers by providing the central charging point for rechargeable electronics and lighting.

Based on the load requirements of the civic center and the water velocity of the river, the battery sized was determined to be 350Ah and the size of the hydrokinetic turbine was evaluated to be $2.5 \mathrm{~kW}$ assuming the coefficient of performance $C_{p}$ of $35 \%$.

The simulation result showing the load profile of the civic center, hydrokinetic power generation using the $2.5 \mathrm{~kW}$ turbine (determined using equation 5) and the battery state of charge (determined using equations 6-7 and equations 9 are depicted in Figure 8.

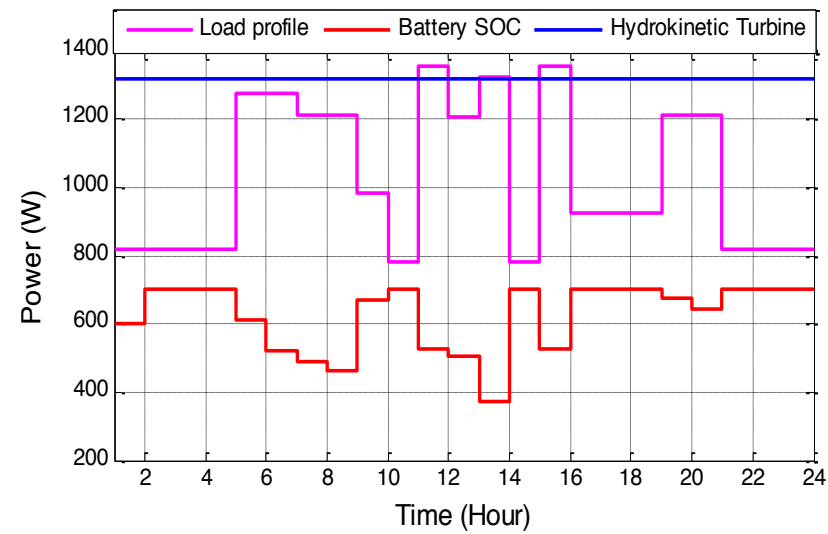

Figure 8. power output of hydrokinetic turbine, state of charge of battery and the load profile of the civic center

The figure reveals that the hydrokinetic turbine generates nearly constant power of about $1.34 \mathrm{~kW}$ throughout the 24 hours period. This is enough to meet the average power demand (about $1 \mathrm{~kW}$ ) of the civic center but will not be able to meet the peak load demand $(1.38 \mathrm{~kW})$. The constant power from the turbine was as a result of nearly constant water flow velocity of about $1.2 \mathrm{~m} / \mathrm{s}$ throughout the entire period. The figure also reveals that the SOC of the battery has a negative correlation with the load profile. This is expected because, whenever there is increase in load demand, more energy is required from the battery to meet the load demand thereby putting the battery in the state of discharge. This is indicated in the figure with the negative trend of the SOC of the battery each time there is an increase in load profile. Similarly, the battery is charged whenever there is decrease in the load demand.

Figure 9 depicts the combination of the battery and the hydrokinetic turbine in meeting the electrical power demands of the civic center. The figure reveals that the hybrid of the battery and hydrokinetic turbine generates peak power of $1.6 \mathrm{~kW}$. This indicates that at any period of time, the hydride configuration will effectively meet the peak power demand $(1.38 \mathrm{~kW})$ of the civic center. The configuration consisting of a $350 \mathrm{Ah}$ battery and $2.5 \mathrm{~kW}$ hydrokinetic turbine

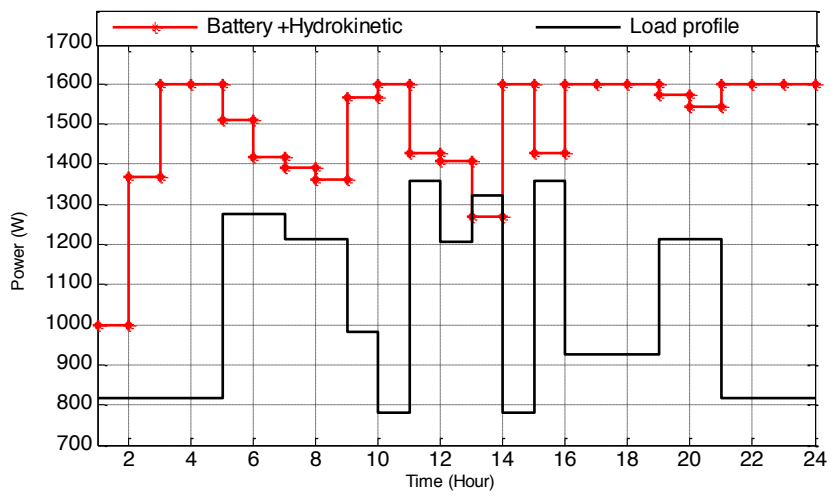

Figure 9. Power output of hybrid of hydrokinetic turbine and battery in meeting the load requirement of civic center

\section{Conclusion}

This paper has investigated the opportunity of hydrokinetic power generation in Nigeria as means of rural electrification. The gaps which can hinder the development of hydrokinetic technology in Nigeria for rural electrification were identified. Also, the potential of some rivers across the country being used for hydrokinetic power generation were explored. This study found that there is huge hydrokinetic potential with an estimated value of $111.15 \mathrm{MW}$ which are untapped in Nigeria. The hydrokinetic potential in Northern part of the country is estimated to be $68.18 \mathrm{MW}$ while that of the Southern part is $42.97 \mathrm{MW}$. A case study conducted using hydrokinetic turbine and battery reveals that the technology is feasible for rural community. This paper is useful as it reveals the hydrokinetic energy potential in Nigeria. It also showcases the potential of using hydrokinetic technology to meet the electrical energy need of isolated communities. Furthermore, it can also serve as first hand useful information for investors and project developers who are interested in rural electrification.

Future research will compare the hydrokinetic technology to other renewable energy generators in term of cost of energy, life cycle cost and reliability in meeting the energy needs of isolated rural communities.

\section{Reference}

Anyi, M., Ali, S. \& Kirke, B., (2009). Remote community electrification. International Conference on Renewable Energies and Power Quality, (ICREPQ'09). Valencia,Spain, 15-17. 
Anyi, M., Kirke, B. \& Ali, S., (2010). Remote community electrification in sarawak, malaysia. Renewable and Sustainable Energy Reviews, 35 (7), 609-613.

Ayodele, T.R., (2014). Feasibility study of stand-alone hybrid energy system for rural electrification in nigeria: The case study of ala-ajagbusi community. International Journal of Renewable Energy Resources, 4, 1-12.

Ayodele, T.R., Ogunjuyigbe, A.S.O. \& Babatunde, J.B., (2016). Sustainable electricity generation in rural communities using hybrid energy system: The case study of ojataye village. International Journal of Renewable Energy, 11 (1), 43-56.

Bertsch, D.J., (2015). Hydrokinetic energy: Trying to navigate the energy and wave law frame work to develop new renewable energy technology. Available from: . http://www.elizabethburleson.com/HydrokineticEnergyDerek Bertsch.pdf, accessed 15th May 2015., Available from: http://www.elizabethburleson.com/Hydrokinetic EnergyDerekBertsch.pdf.

Chen, F., Duic, N., Aives, L.M. \& Carvalho, M.G., (2007). Renewable energy solutions for islands. Renew Sustainable Energy Reviews, 11 (8), 1888-1892.

Coiro, D.P., (2007). Experiments on horizontal and vertical axis water turbines for harnessing marine currents: Technological and economical aspects. www.dpa.unina.it/adag/. Available from: www.dpa.unina.it/adag/.

F.A.O, (2012). Food and agriculture organization of the united nations, hydrology and inland water resources of nigeria, retrieved august $2012 \mathrm{http} / / / \mathrm{www}$. fao.org/docrep., 1-50.

Faure, T.D., Pratte, B.D. \& Swan, D., (1986). The darrieus hydraulic turbine-model and field experiments. Fourth International Symposium on Hydro Power Fluid Machinery: presented at the Winter Annual Meeting of the American Society of Mechanical Engineers. Anaheim, California: American Society of Mechanical Engineers, 123-127.

Gorban, A.N., Gorlov, A.M. \& Silantyev, V.M., (2001). Limits of the turbine efficiency for free fluid flow. Journal of Energy Resources Technology, Transactions of the ASME, 123 (2-4), 311-317.

Güney, M.S. \& Kaygusuz, K., (2010). Hydrokinetic energy conversion systems. Renewable Sustainable Energy Reviews, 14, 2996-3004.

Kaygusuz, K. \& Kaygusuz, A., (2002). Renewable energy and sustainable development in turkey. Renewable Energy 25, 431-453.

Khan, M., J., Bhuyan, G., Iqbal, M.T. \& Quaicoe, J.E., (2008). River current energy conversion systems: Progress, prospects and challenges. Renewable and Sustainable Energy Reviews, 12, 2177-2193.

Khan, M.J., Bhuyan, G., Iqbal, M.T. \& Quaicoe, J.E., (2009). Hydrokinetic energy conversion systems and assessment of horizontal and vertical axis turbines for river and tidal applications: A technology status review. Applied Energy, $1823-1835$

Kusakana, K., (2015). Feasibility analysis of river off-grid hydrokinetic systems with pumped hydro storage in rural application. Energy Conversion and Management, 96, 352362.

Manohar, K. \& Adeyanju, A.A., (2009). Hydropower energy resources in nigeria. Journal of Engineering and Applied Sciences, 4 (1), 68-73.

Ogunjuyigbe, A.S.O., Ayodele, T.R. \& Ibitoye, T.Y., (2015). Review of hydrokinetic energy potential in nigeria. First Faculty of Technology Conference. University of Ibadan, Nigeria, 129-134.

Olatunde, S.O. \& Oladele, O., (2013). Eco-partitioning and indices of heavy metal accumulation in sediment and tilapia zillii fish in water catchment of river niger at ajaokuta, north central nigeria. International Journal of Physical Sciences, 8 (20), 1111-1117.

Sambo, A.S., (2009). Strategic developments in renewable energy in nigeria.
Vermaak, H.J., Kusakana, K. \& S.P., K., (2014). Status of microhydrokinetic river technology in rural applications. Renewable and Sustainable Energy Reviews, 29, 625 - 633.

Zarma, I.H., (2006). Hydropower resources in nigeria. 2nd Hydropower for Today Conference of the International Centre for Small Hydropower (ICSHP), Hangzhou, China. Canada, 3-7.

Zomers, A., (2003). The challenges of rural electrification. Energy for Sustainable Development 7(1), 69-76. 